\title{
Are investors moonstruck? Lunar phases and stock returns
}

\author{
Kathy Yuan ${ }^{\text {a }}$, Lu Zheng ${ }^{\text {a,* }}$, Qiaoqiao Zhu ${ }^{\text {b }}$ \\ ${ }^{\text {a }}$ Stephen M. Ross School of Business, University of Michigan, 701 Tappan Street, Ann Arbor, \\ MI 48109-1234, United States \\ ${ }^{\mathrm{b}}$ University of Michigan, Economic Department, United States
}

Accepted 14 June 2005

\begin{abstract}
This paper investigates the relation between lunar phases and stock market returns of 48 countries. The findings indicate that stock returns are lower on the days around a full moon than on the days around a new moon. The magnitude of the return difference is $3 \%$ to $5 \%$ per annum based on analyses of two global portfolios: one equal-weighted and the other value-weighted. The return difference is not due to changes in stock market volatility or trading volumes. The data show that the lunar effect is not explained away by announcements of macroeconomic indicators, nor is it driven by major global shocks. Moreover, the lunar effect is independent of other calendar-related anomalies such as the January effect, the day-of-week effect, the calendar month effect, and the holiday effect (including lunar holidays).
\end{abstract}

(C) 2005 Elsevier B.V. All rights reserved.

JEL classification: G12; G14

Keywords: Lunar phases; Weather effect; Market efficiency; Global stock market; Calendar anomalies; Individual behavior

"It is the very error of the moon, She comes more near the earth than she was wont. And makes men mad." (Othello, Act V, Scene ii)

\section{Introduction}

The belief that phases of the moon affect mood and behavior dates back to ancient times. The lunar effect on the human body and mind is suggested anecdotally as well as empirically

* Corresponding author.

E-mail addresses: kyuan@umich.edu (K. Yuan), luzheng@umich.edu (L. Zheng), qqzhu@umich.edu (Q. Zhu). 
in the psychological and biological literature. Do lunar phases also affect the securities markets?

If investors make decisions strictly through rational maximization, then the answer is no. However, research evidence suggests that investors are subject to various psychological and behavioral biases when making investment decisions, such as loss-aversion, overconfidence, and mood fluctuation (e.g., Harlow and Brown, 1990; Odean, 1998, 1999). On a general level, numerous psychological studies suggest that mood can affect human judgment and behavior (e.g., Schwarz and Bless, 1991; Frijda, 1998). The behavioral finance literature documents evidence on the effects of mood on asset prices (e.g., Avery and Chevalier, 1999; Kamstra et al., 2000, 2003; Hirshleifer and Shumway, 2003; Coval and Shumway, 2005). If lunar phases affect mood, by extension, these phases may affect investor behavior and thus asset prices. If so, asset returns during full moon phases may be different from those during new moon phases. More specifically, since psychological studies associate full moon phases with depressed mood, this study hypothesizes that stocks are valued less and thus returns are lower during full moon periods.

This study is motivated by a psychological hypothesis. In modern societies the lunar cycle has little tangible impact on people's economic and social activities. Consequently, it would be difficult to find rational explanations for any correlation between lunar phases and stock returns. The causality would be obvious if there is such an effect. Therefore, investigating the lunar effect on stock returns is a strong test of whether investor behavior affects asset prices. Nevertheless, it is also important to recognize the possibility that the relation between lunar phases and stock returns could be spurious. As many researchers study the patterns of historical stock returns, some will find significant results simply due to chance. ${ }^{1}$

To investigate the relation between lunar phases and stock returns, we first examine the association of lunar phases with the returns of an equal-weighted and a value-weighted global portfolio of 48 country stock indices. The findings indicate that global stock returns are significantly lower during full moon periods than new moon periods. For the equal-weighted global portfolio, the cumulative return difference between the new moon periods and the full moon periods is 40.26 bps per lunar cycle for the 15-day window specification and 27.48 bps per lunar cycle for the 7-day window specification; both are significant at the $5 \%$ level. For the value-weighted global portfolio, the corresponding return difference is $30.44 \mathrm{bps}$ for the 15-day window specification and $25.87 \mathrm{bps}$ for the 7 -day window specification, which are significant at the $10 \%$ and the $5 \%$ levels respectively. These numbers translate into annual return differences of $3 \%$ to $5 \%$. The differences in the average daily logarithmic returns between the new and the full moon periods are consistent with the above findings.

A sinusoidal model is also estimated to test for the cyclical pattern of the lunar effect. According to this model, the lunar effect reaches its peak at the time of full moon and declines to a trough at the time of new moon, following a cosine curve with a period of 29.53 days (the mean length of a lunar cycle). The results indicate a significant cyclical lunar pattern in stock returns.

To fully utilize the panel data, a pooled regression was estimated with panel-corrected standard errors (PCSE) for all 48 countries and for the following subgroups of countries: the G-7

\footnotetext{
${ }^{1}$ For example, Sullivan et al. (1999) argue that data snooping biases occur when a given set of data is used more than once for the purpose of model selection or inference. When such data reuse happens, there is always a possibility that results are due to chance rather than any merits inherit in the method. They quantify the data-snooping bias and adjust for its effect in the context of technical trading rules.
} 
countries, the other developed countries, and the emerging-market countries. The PCSE specification adjusts for the contemporaneous correlation and heteroscedasticity among country index returns, as well as for the autocorrelation within each country's stock index returns. When all countries are included in the analysis, a statistically significant relation is found between moon phases and stock returns for both the 15-day and 7-day window specifications. Stock returns are, on average, 4 bps lower daily (about 5\% annually) for the 15 days around the full moon than for the 15 days around the new moon. Using a 7-day window, stock returns are, on average, 6 bps lower daily (about 4\% annually) on the full moon days than on the new moon days. The estimated effect remains similar when country group fixed effects are included. When country fixed effects are included, the estimated lunar effect becomes stronger. Another interesting observation is that the magnitude of this lunar effect is larger in the emerging market countries than in the developed countries.

To study the relation between the lunar effect and investor sentiment, we examine whether the lunar effect on stock returns is related to stock size, and thus individual versus institutional decision-making, since institutional ownership is higher for large cap stocks. Indeed, for U.S. stocks, we find evidence that the lunar effect is more pronounced for NASDAQ and small cap stocks than for NYSE-AMEX and large cap stocks. ${ }^{2}$ Thus, the evidence suggests that the lunar effect is stronger for stocks that are held mostly by individuals. This finding is consistent with the notion that lunar phases affect individual moods, which in turn affect investment behavior.

To better understand the relation between lunar phases and stock markets, we investigate whether lunar phases relate to stock trading volumes and return volatility. No evidence is found that the lunar effect observed in stock returns is associated with trading volumes or risk differentials during the full moon and the new moon periods.

We then examine whether the lunar effect can be explained by macroeconomic events and other documented calendar anomalies. The findings indicate that the lunar effect is not due to the average effect of macroeconomic announcements or the changes in the short-term interest rates. Nor can the lunar effect be fully explained by global shocks. The lunar effect remains similar after we control for other calendar-related anomalies, such as the January effect, the day-of-week effect, the calendar month effect, and the holiday effects (including lunar holidays). Thus, we conclude that the lunar effect is unlikely a manifestation of these calendar anomalies. We further check the robustness of the lunar effect using various lunar window lengths, alternative ARIMA specifications, and a test of random 30-day cycles.

The remainder of the paper is organized as follows. Section 2 discusses the literature on how lunar phases affect human mood and behavior. Section 3 describes the data. Section 4 discusses the methodology and results. Section 5 concludes.

\section{Literature review}

One difficulty in testing whether psychological biases and sentiments affect investor trading behavior and asset prices is to find a proxy variable for sentiment or mood that is observable and exogenous to economic variables. Nonetheless, there have been several creative attempts. For example, Avery and Chevalier (1999) show that sentimental bettors can affect the path of prices in football betting. Saunders (1993) and Hirshleifer and Shumway (2003), drawing on

\footnotetext{
${ }^{2}$ The exception is for the smallest size decile in NASDAQ stocks. Market microstructure and liquidity-related issues are more likely to have a significant impact on the pricing of extremely small stocks.
} 
psychological evidence that sunny weather is associated with an upbeat mood, find that sunshine is strongly correlated with stock returns. In a study of the seasonal-variation of risk premia in stock market returns, Kamstra et al. (2003) draw on a documented medical phenomenon, Seasonal Affective Disorder (SAD), to proxy investor mood and find a statistically significant relation between SAD and stock market returns. In another study, Kamstra et al. (2000) relate yearly daylight fluctuations to mood changes and in turn to stock market returns.

This paper exploits the popular perception that lunar phases affect mood and behavior, and analyzes the relation between lunar phases and stock returns. The hypothesis is that the lunar effect is an exogenous proxy for mood since lunar phases do not have tangible effects on economic and social activities. Furthermore, while the level of sunshine studied in Hirshleifer and Shumway (2003) is specific to geographical locations, lunar cycles are the same around the globe. Thus the lunar effect does not depend on the geographical locations of investors. Lunar cycles are also predictable. A relation between lunar cycles and stock returns will indicate that stock prices are predictable in a way uncorrelated with economic fundamentals, which is a strong violation of the efficient market hypothesis.

The idea that the moon affects individual moods has ancient roots. The moon has been associated with mental disorder since ancient time, as reflected by the word "lunacy", which derives from Luna, the Roman goddess of the moon. Popular belief has linked the full moon to such disparate events as epilepsy, somnambulism, crime, suicide, mental illness, disasters, accidents, birthrates, and fertility.

Biological evidence suggests that lunar phases have an impact on the human body and behavior. Research on biological rhythms documents a circatrigintan cycle, which is a moonrelated human cycle. The most common monthly cycle is menstruation. A woman's menstrual cycle is about the same length as a lunar cycle, which suggests the influence of the moon. Law (1986) finds a synchronous relationship between the menstrual cycle and the lunar phases. Studies also find a lunar effect on fertility; for example, Criss and Marcum (1981) document that births vary systematically over lunar cycles with peak fertility during the third lunar quarter. In addition, lunar phases affect human nutrient intake: de Castro and Pearcey (1995) document an $8 \%$ increase in meal size and a $26 \%$ decrease in alcohol intake at the time of full moon.

Much attention has been paid to the lunar effect on human mood and behavior in the psychology literature. A recent study by Neal and Colledge (2000) documents an increase in general practice consultations during the full moon phase. Liber (1978) and Tasso and Miller (1976) indicate a disproportionately higher number of criminal offences occur during the full moon phase. Weiskott (1974) reports evidence that the number of crisis calls is higher during full moon and waning phases. Hicks-Caskey and Potter (1991) suggest an effect of the day of a full moon on the acting-out behavior of developmentally delayed, institutionalized women. Sands and Miller (1991) document that a full moon is associated with a significant but slight decrease in absenteeism after controlling for the effects of the day of the week, month, and proximity to a holiday.

Overall, the effect of the moon has been studied informally and formally for years. However, despite the attention this effect has received, psychological evidence for the lunar hypothesis in general is not conclusive even though biological evidence is strong. For example, in a review of empirical studies, Campbell and Beets (1978) conclude that lunar phases have little effect on psychiatric hospital admissions, suicides, or homicides. On the other hand, researchers argue that this lack of relation does not preclude a lunar effect. It may simply mean that the effect has not been adequately tested due to small sample sizes and short sample time periods (Cyr and Kaplan, 1987; Garzino, 1982). Moreover, the psychology literature has mainly focused on trying to link 
the moon's phases to extreme behavioral problems in a few disturbed people, rather than a less drastic effect on human beings in general. By studying the relation between lunar phases and asset prices, this paper extends the literature of the lunar effect on behavior.

In addition, survey evidence suggests a wide belief in the lunar effect. Rotton and Kelly (1985a) find that $49.4 \%$ of the respondents to their survey believe in lunar phenomena. Interestingly, among psychiatric nurses, this percentage rises to 74\% (Agus, 1973). Vance (1995) reports a similar result. Danzl (1987) finds survey evidence that $80 \%$ of the nurses and $64 \%$ of the physicians in the emergency department believe that the moon cycle affects patients. Scientific explanations have been proposed to account for the moon's effect on the brain: sleep deprivation, heavy nocturnal dew, tidal effect, weather patterns, magnetism and polarization of the moon's light (Kelley, 1942; Katzeff, 1981; Szpir, 1996; Raison et al., 1999).

Given the extensive documentation of the correlation between lunar phases and human feelings, thoughts, and behaviors, more specifically, the correlation between full moon periods and sleep deprivation, depressed mood, and suicidal events, the hypothesis in this study is that investors may value financial assets less during full moon periods than during new moon periods due to the changes in mood associated with lunar phases. ${ }^{3}$

This paper is not the first attempt to link lunar phases to stock returns. Rotton and Kelly (1985b) cite a working paper by Rotton and Rosenberg (1984) that investigates the relation between lunar phases and Dow Jones average closing prices. They find no significant relation between lunar phases and the Dow Jones Index prices. ${ }^{4}$ The current study differs in that it examines returns rather than prices. In addition, heteroscedasticity and autocorrelations are corrected for in the return series, thus providing a more precise test for the relation. Most importantly, a broad sample of 48 countries is examined, which constitutes a more comprehensive and powerful test. Dichev and Janes (2003) also report a significant lunar effect on stock returns. Their study is concurrent with and independent of this study. Their findings and the findings of this paper complement each other. Dichev and Janes (2003) focus more on the U.S. market, while this paper provides global evidence on 48 countries with different levels of market development.

\section{Data}

A lunar calendar was obtained from the United States Naval Observatory (USNO) website. ${ }^{5}$ This site provides the date and time (Greenwich Mean Time) of four phases of the moon for the time period of 1700 to 2015. The four phases are: new moon, first quarter, full moon and last quarter. For the year 2000, the length of the mean synodic month (new moon to new moon) is 29.53059 days.

Stock market information on returns and trading volumes was obtained through Datastream. The sample period is from January 1973 to July 2001. The return sample consists of 48 countries listed in Morgan Stanley Capital International (MSCI) as developed markets or emerging

\footnotetext{
${ }^{3}$ We follow the evidence and argument in Hirshleifer and Shumway (2003) that good mood is associated with high asset returns. Since we assume that investors' mood follows a sinusoidal model and positive mood is associated with high asset returns, the hypothesis corresponds to a cycle in returns that meets its peak at new moon and its trough at the full moon.

${ }^{4}$ We were unable to obtain the working paper by Rotton and Rosenberg (1984). Our comments are based on the discussion provided in Rotton and Kelly (1985b).

5 http://aa.usno.navy.mil/AA/.
} 
Table 1

Summary statistics

\begin{tabular}{|c|c|c|c|c|c|}
\hline Country & Code & Starting date & $\begin{array}{l}\text { Number of } \\
\text { observations }\end{array}$ & $\begin{array}{l}\text { Mean daily } \\
\text { log return }\end{array}$ & $\begin{array}{l}\text { Std. dev. of } \\
\text { daily log return }\end{array}$ \\
\hline Argentina & TOTMKAR & $1 / 88$ & 3510 & 28.42 & 360.60 \\
\hline Australia & TOTMKAU & $1 / 73$ & 7213 & 3.35 & 111.79 \\
\hline Austria & TOTMKOE & $1 / 74$ & 6355 & 2.55 & 86.00 \\
\hline Belgium & TOTMKBG & $1 / 73$ & 7124 & 2.96 & 82.26 \\
\hline Brazil & BRBOVES & $1 / 72$ & 2475 & 57.11 & 646.73 \\
\hline Canada & TOTMKCN & $1 / 73$ & 7226 & 2.97 & 84.13 \\
\hline Chile & TOTMKCL & $7 / 89$ & 3013 & 8.14 & 103.21 \\
\hline China & ТОТМКСН & $1 / 91$ & 2443 & 11.36 & 291.94 \\
\hline Czech & CZPX50I & $4 / 94$ & 1750 & -5.50 & 127.19 \\
\hline Denmark & TOTMKDK & $1 / 74$ & 6377 & 5.34 & 108.49 \\
\hline Finland & TOTMKFN & $1 / 88$ & 3339 & 5.46 & 183.89 \\
\hline France & TOTMKFR & $1 / 73$ & 7264 & 4.17 & 111.26 \\
\hline Germany & TOTMKBD & $1 / 73$ & 7192 & 2.72 & 95.33 \\
\hline Greece & TOTMKGR & $1 / 88$ & 3385 & 7.86 & 191.51 \\
\hline Hong Kong & TOTMКНК & $1 / 73$ & 7103 & 3.97 & 192.03 \\
\hline Hungary & BUXINDX & $2 / 91$ & 2629 & 7.17 & 177.12 \\
\hline India & IBOMBSE & $4 / 84$ & 2903 & 6.29 & 188.61 \\
\hline Indonesia & TOTMKID & $4 / 84$ & 2761 & -1.18 & 251.78 \\
\hline Ireland & TOTMKIR & $1 / 73$ & 7103 & 4.69 & 108.82 \\
\hline Israel & ISTGNRL & $1 / 84$ & 4179 & 14.25 & 143.62 \\
\hline Italy & TOTMKIT & $1 / 73$ & 7445 & 4.33 & 134.20 \\
\hline Japan & TOTMKJP & $1 / 73$ & 7145 & 1.81 & 101.45 \\
\hline Jordan & AMMANFM & $11 / 88$ & 2176 & 2.68 & 86.07 \\
\hline Korea & TOTMKKO & $1 / 75$ & 3322 & 1.04 & 207.68 \\
\hline Luxembourg & TOTMKLX & $1 / 92$ & 2370 & 5.65 & 100.19 \\
\hline Malaysia & TOTMKMY & $1 / 88$ & 3349 & 3.52 & 164.16 \\
\hline Mexico & TOTMKMX & $1 / 88$ & 3436 & 11.71 & 170.90 \\
\hline Morocco & MDCFG25 & $12 / 87$ & 1820 & 11.99 & 91.44 \\
\hline Netherlands & TOTMKNL & $1 / 73$ & 7219 & 3.51 & 95.83 \\
\hline New Zealand & TOTMKNZ & $1 / 88$ & 3409 & 1.71 & 114.76 \\
\hline Norway & TOTMKNW & $1 / 80$ & 5419 & 3.99 & 142.43 \\
\hline Pakistan & PKSE100 & $12 / 88$ & 2795 & 2.63 & 162.94 \\
\hline Peru & PEGENRL & $1 / 91$ & 2597 & 15.25 & 158.34 \\
\hline Philippines & TOTMКРН & $9 / 87$ & 3464 & 4.86 & 154.32 \\
\hline Poland & ТОТМКРО & $1 / 94$ & 1803 & -2.07 & 231.97 \\
\hline Portugal & TOTMKРТ & $1 / 90$ & 2858 & 1.76 & 93.31 \\
\hline Russia & RSMTIND & 9/94 & 1676 & 18.85 & 369.42 \\
\hline Singapore & TOTMKSG & $1 / 73$ & 7128 & 1.20 & 144.94 \\
\hline South Africa & TOTMKSA & $1 / 73$ & 7170 & 5.53 & 135.84 \\
\hline Spain & TOTMKES & $1 / 88$ & 3623 & 3.34 & 116.10 \\
\hline Sweden & TOTMKSD & $1 / 82$ & 4903 & 6.07 & 134.73 \\
\hline Switzerland & TOTMKSW & $1 / 73$ & 7174 & 2.87 & 85.17 \\
\hline Taiwan & TOTMKTA & $9 / 87$ & 3371 & 1.89 & 223.19 \\
\hline Thailand & TOTMKTH & $1 / 88$ & 3349 & 2.09 & 200.12 \\
\hline Turkey & TOTMКТК & $1 / 88$ & 3467 & 21.28 & 298.62 \\
\hline United Kingdom & TOTMKUK & $1 / 73$ & 7258 & 3.78 & 103.42 \\
\hline United States & TOTMKUS & $1 / 73$ & 7216 & 3.26 & 98.80 \\
\hline Venezuela & TOTMKVE & $1 / 90$ & 2829 & 12.72 & 249.88 \\
\hline Global Portfolio & Equal-weighted & $1 / 73$ & 7456 & 5.38 & 58.93 \\
\hline Global Portfolio & Value-weighted & $1 / 73$ & 7456 & 3.07 & 67.40 \\
\hline
\end{tabular}

This table reports the summary statistics for the 48 country stock indices. All sample periods end on July 31, 2001. All returns are in basis points. 
markets. The country index calculated by Datastream (Datastream Total Market Index) was used unless a country did not have this series for at least 5 years; in these cases, the country index from other sources in Datastream was used. All returns were measured as nominal returns in local currencies. Trading volume data was collected for 40 of the corresponding 48 stock indices. Eight of these 48 indices did not have trading volume data in Datastream. Summary statistics appear in Table 1 .

\section{Empirical findings}

This section describes the empirical results of testing the hypothesis that stock returns are associated with lunar phases. We first report findings using an equal-weighted and a valueweighted global portfolio of the 48 country stock indices. This set of results indicates the significance of lunar effect on global stock returns.

Next, a panel regression was estimated using the entire panel of countries as well as panels of the following country categorizations: the G-7 countries, the other developed countries, and the emerging market countries.

To better understand the lunar effect on stock returns, we examine whether such an effect is related to stock capitalizations, patterns in trading volumes and stock market volatility. We also investigate whether the lunar effect is driven by macroeconomic announcements, global shocks, and calendar-related anomalies, such as the January effect, the day-of-week effect, the calendar month effect, the holiday effect, and the lunar holiday effect. Finally we check the robustness of the lunar effect to various lunar window lengths, several ARIMA specifications, and a test of random 30-day cycles.

\subsection{Lunar effect on the global portfolios}

Since lunar cycles are common across the globe, we examine the lunar effect on an equal-weighted and a value-weighted global portfolio of 48 countries. ${ }^{6}$ Specifically, we compare the returns of the full moon periods to the returns of the new moon periods for the global portfolios. Table 2 reports the test results. Panel A presents average cumulative returns; Panel B presents average daily logarithmic returns. The results indicate that the returns during the new moon periods are significantly higher than those during the full moon periods. ${ }^{7}$ The effect is stronger for the 7-day window specification than for the 15-day window specification. The effect is also stronger for the equal-weighted portfolio than for the value-weighted portfolio. The findings are consistent regardless of using cumulative returns or daily logarithmic returns.

In Table 2, Panel A, the cumulative return difference is -40.26 bps per lunar cycle for the 15 day window specification and -27.48 bps per lunar cycle for the 7 -day window specification. A trading strategy with a long position in the portfolio during the new moon periods and a short position during the full moon periods on average yields a return of $40.26 \mathrm{bps}$ for a lunar month

\footnotetext{
${ }^{6}$ At each point of time, we form the global portfolio using countries for which the return information is available.

${ }^{7}$ A full moon period is defined as $N$ days before the full moon day + the full moon day $+N$ days after the full moon day $(N=3$ or 7). Similarly, a new moon period is defined as $N$ days before the new moon day + the new moon day $+N$ days after the new moon day $(N=3$ or 7$)$. In the case of the 15-day window, a new moon period can be less than 15 days since a lunar month may be less than 30 days. In these cases, the new moon period is defined as the remaining days of the lunar month.
} 
Table 2

Lunar phases and stock returns: the global portfolio

\begin{tabular}{|c|c|c|c|c|}
\hline & \multicolumn{2}{|l|}{ 15-Day window } & \multicolumn{2}{|l|}{ 7-Day window } \\
\hline & $\begin{array}{l}\text { Equal-weighted } \\
\text { global portfolio }\end{array}$ & $\begin{array}{l}\text { Value-weighted } \\
\text { global portfolio }\end{array}$ & $\begin{array}{l}\text { Equal-weighted } \\
\text { global portfolio }\end{array}$ & $\begin{array}{l}\text { Value-weighted } \\
\text { global portfolio }\end{array}$ \\
\hline \multicolumn{5}{|l|}{ Panel A: average cumulative returns } \\
\hline Full moon return-new moon return & -40.26 & -30.44 & -27.48 & -25.87 \\
\hline Newey-West adjusted $T$-statistic (AR1) & $(-2.40)$ & $(-1.87)$ & $(-3.46)$ & $(-2.40)$ \\
\hline Newey-West adjusted $T$-statistic (AR2) & $(-2.82)$ & $(-1.94)$ & $(-3.46)$ & $(-2.39)$ \\
\hline Newey-West adjusted $T$-statistics (AR3) & $(-2.99)$ & $(-1.99)$ & $(-3.54)$ & $(-2.37)$ \\
\hline Bootstrapped $p$-value & $(0.01)$ & $(0.07)$ & $(0.01)$ & $(0.00)$ \\
\hline Signed-rank test ( $p$-value) & $(0.00)$ & $(0.02)$ & $(0.00)$ & $(0.01)$ \\
\hline \multicolumn{5}{|l|}{ Panel B: average daily logarithmic returns } \\
\hline Full moon return-new moon return & -3.53 & -2.80 & -4.94 & -4.82 \\
\hline Newey-West adjusted $T$-statistic (AR1) & $(-2.61)$ & $(-1.75)$ & $(-2.68)$ & $(-2.02)$ \\
\hline Newey-West adjusted $T$-statistic (AR2) & $(-2.82)$ & $(-1.82)$ & $(-2.74)$ & $(-2.03)$ \\
\hline Newey-West adjusted $T$-statistics (AR3) & $(-2.95)$ & $(-1.86)$ & $(-2.81)$ & $(-2.04)$ \\
\hline Bootstrapped $p$-value & $(0.02)$ & $(0.05)$ & $(0.02)$ & $(0.03)$ \\
\hline Signed-rank test ( $p$-value) & $(0.00)$ & $(0.02)$ & $(0.00)$ & $(0.02)$ \\
\hline
\end{tabular}

This table compares the returns of the equal-weighted and value-weighted global portfolio between the full moon and the new moon periods. We define the full moon and the new moon periods using the 15-day and the 7-day windows. In the 15-day window analysis, the full moon period is 7 days before and after the full moon day plus the full moon day; the new moon period is defined as the rest of the lunar month. In the 7-day window analysis, the full (new) moon period is 3 days before and after the full (new) moon day plus the full (new) moon day. Panel A examines the average cumulative returns and Panel B examines the average daily logarithmic returns. We report Newey-West adjusted $T$-statistics, $p$-values from bootstrap analysis and signed-rank test. The returns are in basis points.

using the 15-day window specification. A similar strategy using the 7-day window specification yields a return of 27.48 bps. These numbers translate into annual returns of $4.8 \%(40.26$ bps*12) and 3.3\% (27.48 bps*12) for the trading strategies, both significant at the 5\% level. For the value-weighed portfolio, the corresponding return differences are $-30.44 \mathrm{bps}$ for the 15 -day window and -25.87 bps for the 7 -day window. These numbers translate into annual returns of $3.7 \%(30.44 \mathrm{bps} * 12)$ and $3.1 \%(25.87 \mathrm{bps} * 12)$ for the corresponding trading strategies using the value-weighted portfolio. To further gauge the economic significance, the transaction cost of implementing this trading strategy was estimated using exchange-traded funds. The bid-ask spread for emerging market ETFs, such as iShares MSCI Emerging Markets $\mathrm{ETF}^{8}$ typically is around $0.10 \%$ of the traded value. Since the trading strategy used here involves 12 round-trip transactions (i.e., 24 transactions), a rough estimate of the transaction cost is $1.2 \%$. Hence, the annual returns net of transaction costs for the trading strategies range from $1.9 \%$ to $3.6 \%$.

Consistent with the evidence in Panel A, Panel B shows that the mean daily logarithmic returns are lower for the full moon periods than for the new moon periods. The average daily return difference for the equal-weighted portfolio is $-3.53 \mathrm{bps}$ for the 15-day window specification and -4.94 bps for the 7-day window specification. For the value-weighted portfolio, the average daily return difference is $-2.80 \mathrm{bps}$ for the 15-day window specification and -4.82 bps for the 7-day window specification. These numbers translate into annual returns

\footnotetext{
${ }^{8}$ The ticker symbol of ishares MSCI Emerging Markets ETF is EEM and was incepted on April 7, 2003.
} 
of $4.4 \%(=3.53$ bps* 125$)$ and $3.1 \%(=4.94 \mathrm{bps} * 62)$ for the corresponding trading strategies using the equal-weighted portfolio and annual returns of $3.5 \%(=2.80 \mathrm{bps} * 125)$ and $3.0 \%$ $(=4.82 \mathrm{bps} * 62)$ for the trading strategies using the value-weighted portfolio respectively. Again, the lunar effect is stronger for the 7-day window specification and for the equal-weighted portfolio. Fig. 1 plots the corresponding average daily logarithmic returns of the equal-weighted global portfolio for the full moon periods versus the new moon periods.

The documented return differences in both panels in Table 2 are statistically significant. The results are similar when alternative AR specifications of the Newey-West (Newey and West, 1987 ) estimates are used. The bootstrapped $p$-values further confirm that the return differences are unlikely driven by the non-normality of the return distributions and by pure chance. The $p$ values of the nonparametric signed-rank test are all less than $5 \%$.

Next, a sinusoidal model of continuous lunar impact is used to test for the cyclical pattern of the lunar effect. According to the model, the lunar effect reaches its peak at the time of the full moon and declines to the trough at the time of the new moon, following a cosine curve with a period of 29.53 days (the mean length of a lunar cycle). The following regression is estimated for the portfolios:

$$
R_{t}=\alpha+\beta^{*} \cos \left(2 \pi d_{t} / 29.53\right)+e_{t},
$$

where $d$ is the number of days since the last full moon day and the $\beta$ coefficient indicates the association between stock returns and lunar cycles. There is a negative relation $(\beta=-2.88)$ between the global stock returns and lunar cycles. The test result is statistically significant at the $1 \%$ level (Fig. 2). Overall, the sinusoidal model suggests that the lunar effect is cyclical.

In summary, we find global evidence of a significant correlation between stock returns and lunar phases. We document that on average returns are higher during the new moon periods than during the full moon periods.

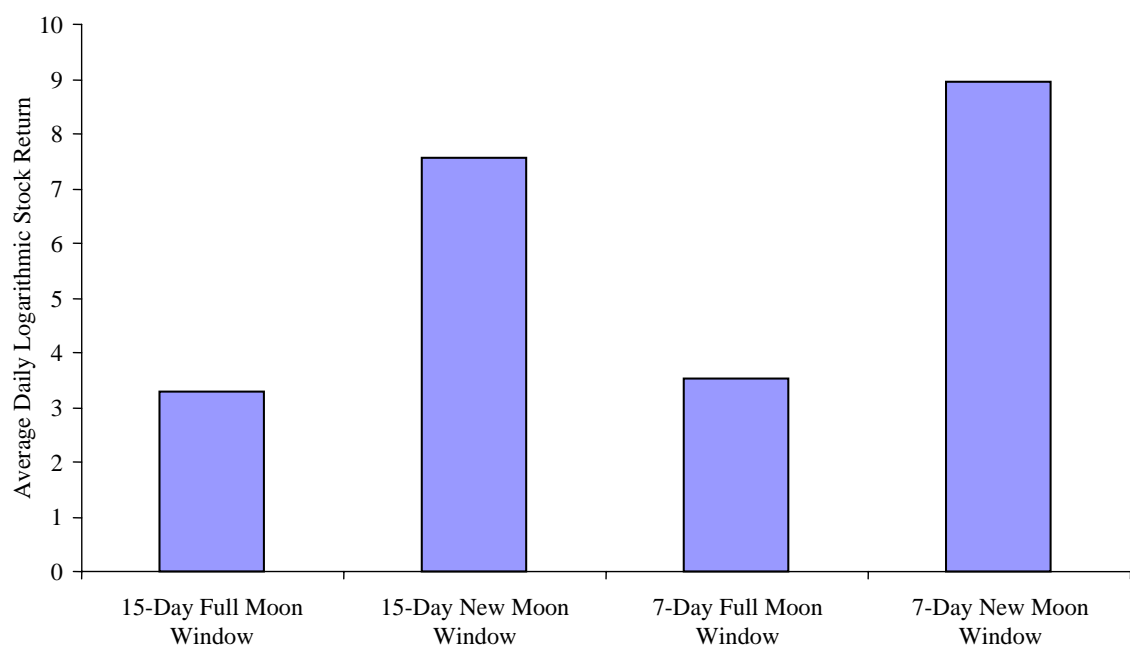

Fig. 1. Average daily logarithmic stock returns of the global portfolio by lunar phases. This figure plots the average daily stock returns of an equal-weighted global portfolio of the 48 country stock indices in a full moon period and a new moon period. The two bars on the left are average returns of a 15-day window; the two bars on the right are average returns of a 7-day window. All returns are in basis points. 


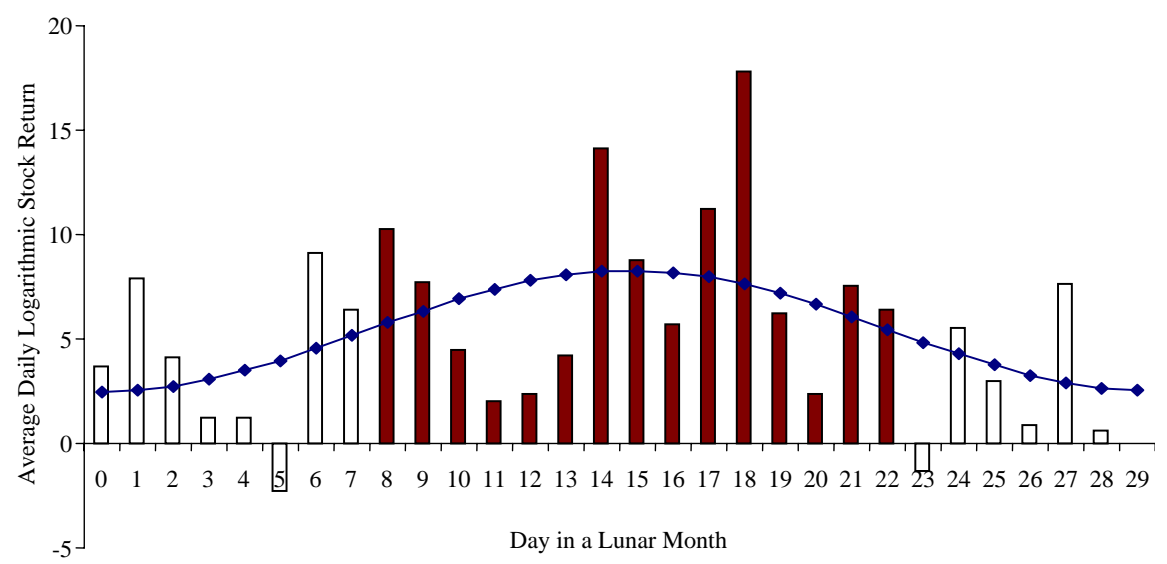

Fig. 2. Average daily logarithmic return of the global portfolio by lunar dates. This figure graphs, for each day of a lunar month, the average daily logarithmic stock returns of an equal-weighted global portfolio of the 48 country stock indices. Day 0 is a full moon day and day 15 is around a new moon day (day 15 is around new moon day since the length of a lunar month varies). The curved line is the estimated sinusoidal model of the lunar effect on stock returns from the following estimated equation: $R_{t}=5.38-2.88 * \cos (2 \pi d / 29.53)$, where $d$ is the number of days since the last full moon.

\subsection{Panel analysis}

A panel of country level average daily logarithmic returns for each lunar period is set up to fully utilize the cross-sectional and time series data. We estimate a pooled regression with panel corrected standard errors (PCSE) as the following:

$$
R_{i t}=\alpha_{i}+\beta^{*} \text { Lunardummy }_{t}+e_{i t} .
$$

$R_{i t}$ is the average daily logarithmic return during a full moon or a new moon period for country $i$ at time $t$. Lunardummy is a dummy variable indicating a full moon or a new moon period; it takes on a value of one for a full moon period and zero for a new moon period. ${ }^{9}$ The coefficient on this variable indicates the difference in the mean daily logarithmic returns between the lunar periods. The PCSE specification adjusts for the contemporaneous correlation and heteroscedasticity among country index returns, as well as for the autocorrelation within each country's stock index returns (Beck and Katz, 1995).

Table 3 presents estimation results of the pooled regression for both the 15-day and the 7day window specifications. The results indicate that stock returns of the new moon periods are significantly higher than those of the full moon periods. Regardless of model specifications, the coefficients on Lunardummy are negative. When all countries are included in the analysis, the returns of the new moon periods are on average 3.95 bps and 5.93 bps higher than returns of the full moon periods for the 15-day and 7-day windows respectively. Both estimates are significant at the 5\% level. The estimated coefficients on the Lunardummy remain similar when country group dummy variables are included. When country fixed effects are included, the estimated coefficients become larger in magnitude and higher in statistical significance. Interestingly, the extent of the lunar effect seems to vary across different levels of market

\footnotetext{
${ }^{9}$ For the 7-day window specification, we only include days of a full moon period and a new moon period. Other days of a lunar month are excluded from the regression.
} 
Table 3

Lunar phases and stock returns: joint tests

\begin{tabular}{|c|c|c|}
\hline & \multicolumn{2}{|l|}{ Lunar dummy $(\beta)$} \\
\hline & 15-Day window & 7-Day window \\
\hline G7 & $-2.43(-1.53)$ & $-2.45(-1.09)$ \\
\hline Other developed markets & $-3.21 * *(-2.08)$ & $-3.19(-1.47)$ \\
\hline Emerging markets & $-5.60 * *(-2.11)$ & $-11.27 * * *(-3.12)$ \\
\hline All markets & $-3.95 * *(-2.25)$ & $-5.93 * *(-2.44)$ \\
\hline All markets with country group dummies & $-3.94 * *(-2.24)$ & $-5.92 * *(-2.43)$ \\
\hline All markets with country fixed effects & $-4.63 * * *(-3.54)$ & $-8.19 * * *(-3.59)$ \\
\hline
\end{tabular}

This table reports the estimates of a pooled regression with panel corrected standard errors $(\mathrm{PCSE}): R_{i t}=\alpha_{i}+$ $\beta *$ Lunardummy ${ }_{t}+e_{i t}$ for the 15-day window and 7-day window, respectively, where $R_{i t}$ is average daily logarithmic returns for country $i$ in lunar month $t$ for each full moon and new moon period. Lunardummy is a dummy variable equal to one if it is a full moon period and zero if it is a new moon period. We define the full moon and the new moon periods using the 15-day and the 7-day windows. In the 15-day window specification, we define the full moon period as 7 days before and after the full moon day plus the full moon day, and define the new moon period as the rest of the lunar month. In the 7-day window specification, we define the full (new) moon period as 3 days before and after the full (new) moon day plus the full (new) moon day. The PCSE specification adjusts for the contemporaneous correlation and heteroscedasticity among country indices and for the autocorrelation within each country's stock index. T-statistics are reported in the parentheses. The daily returns are in basis points.

$*$, **, and $* * *$ denote significance at the $10 \%, 5 \%$, and $1 \%$ levels, respectively, using a two-tailed test.

maturity. The strongest lunar effect is found among the emerging market countries: a 5.60 bps daily difference for the 15-day window and an $11.27 \mathrm{bps}$ daily difference for the 7-day window; both are significant at the 5\% level. The lunar effect in the other developed markets and the G-7 countries is less strong: a 3.21 bps daily difference for the 15-day window and a $3.19 \mathrm{bps}$ daily difference for the 7-day window for the other developed markets; and a 2.43 bps daily difference for the 15-day window and a 2.45 bps daily difference for the 7-day window for the G-7 countries. ${ }^{10}$

In summary, the panel analysis confirms the earlier findings using the global portfolio: stock returns of the new moon periods are significantly higher than those of the full moon periods, more so for the emerging market countries. Maturity of the stock markets and the percentage of institutional investors might explain the differences in the magnitude of lunar impact in these markets.

\subsection{Large versus small capitalization stocks}

In this section, we examine whether the lunar effect is related to stock capitalization. This test is motivated by the empirical finding that institutional ownership is positively correlated with stock capitalization. ${ }^{11}$ Specifically, large capitalization stocks have a higher percentage of institutional ownership than small capitalization stocks. Since investment decisions of individual investors are more likely to be affected by sentiments and mood than those of institutional investors, we expect the lunar effect to be more pronounced in the pricing of small capitalization stocks. To assess the relation between lunar phases and stock capitalization, 10 stock portfolios were formed based on market capitalization for stocks traded on the NYSE, AMEX and

\footnotetext{
${ }^{10} R^{2}$ statistics for these regressions are between $0.1 \%$ and $0.5 \%$. The values are low but not very surprising since we do not expect that the lunar effect would explain a large proportion of variations in stock returns.

${ }^{11}$ For example, see Sias and Starks (1997).
} 
Table 4

Lunar effect and stock sizes

\begin{tabular}{|c|c|c|c|}
\hline \multirow[t]{2}{*}{ Decile } & \multicolumn{3}{|l|}{ Lunar dummy $(\beta)$} \\
\hline & NYSE and AMEX & \multicolumn{2}{|l|}{ NASDAQ } \\
\hline 1 & $-0.660(-0.19)$ & \multicolumn{2}{|l|}{$-3.20 *(-1.66)$} \\
\hline 2 & $-2.73(-1.07)$ & \multicolumn{2}{|l|}{$-3.44 *(-1.86)$} \\
\hline 3 & $-2.05(-0.87)$ & \multicolumn{2}{|l|}{$-3.93 * *(-2.01)$} \\
\hline 4 & $-2.94(-1.34)$ & \multicolumn{2}{|l|}{$-4.08 * *(-2.00)$} \\
\hline 5 & $-2.71(-1.26)$ & \multicolumn{2}{|l|}{$-3.33(-1.54)$} \\
\hline 6 & $-3.01(-1.41)$ & \multicolumn{2}{|l|}{$-4.08 *(-1.80)$} \\
\hline 7 & $-2.84(-1.32)$ & \multicolumn{2}{|l|}{$-3.84(-1.57)$} \\
\hline 8 & $-2.91(-1.35)$ & \multicolumn{2}{|l|}{$-3.97(-1.58)$} \\
\hline 9 & $-3.35(-1.56)$ & \multicolumn{2}{|l|}{$-5.52 *(-1.94)$} \\
\hline \multirow[t]{2}{*}{10} & $-3.03(-1.30)$ & \multicolumn{2}{|l|}{$-2.16(-0.65)$} \\
\hline & Deciles $1-10$ & Deciles $1-10$ & Deciles 1-9 \\
\hline Spearman rank correlation ( $p$-value) & $-0.81 * * *(0.005)$ & $-0.20(0.578)$ & $-0.65 *(0.056)$ \\
\hline
\end{tabular}

This table reports results from estimating a regression of daily returns of market capitalization ranked portfolios on lunar phases. The portfolios are constructed using stocks traded in the U.S. markets: NYSE and AMEX, and NASDAQ, respectively. Decile 1 corresponds to the largest market capitalization stocks. The following regression is used for each portfolio: $R_{t}=\alpha+\beta$ * Lunardummy ${ }_{t}+e_{t}$. Lunardummy is a dummy variable indicating the phase of a lunar cycle, equal to one during a full moon period and zero during a new moon period. The full moon period is 7 days before and after the full moon day plus the full moon day, and the new moon period is the rest of the lunar month. T-statistics with the NeweyWest robust standard errors are in the parentheses. The daily returns are in basis points.

$*, * *$, and $* * *$ denote significance at the $10 \%, 5 \%$, and $1 \%$ levels, respectively, using a two-tailed test.

NASDAQ. Returns and market capitalization for the NYSE, AMEX, and NASDAQ stocks were obtained from CRSP.

Table 4 reports results of a regression of daily returns of market capitalization ranked portfolios on lunar phases. The estimated lunar effect is stronger for NASDAQ stocks than for NYSE and AMEX stocks. Moreover, the lunar effect is stronger for smaller size deciles with the exception of the smallest decile in NASDAQ. ${ }^{12}$ The Spearman rank correlation is -0.81 for the NYSE and AMEX deciles and significant at the $1 \%$ level. The correlation is -0.65 for the NASDAQ deciles and significant at the $10 \%$ level (excluding the smallest decile).

Overall, these findings are consistent with the hypothesis that stocks with more individual investor ownership display a stronger lunar effect and thus provide further evidence that mood or sentiment may affect asset prices.

\subsection{Trading volume and market volatility}

In order to determine whether the observed lunar effect is related to trading volumes and return volatility, we estimate the following regressions for an equal-weighted portfolio and a panel of 48 countries for the 15-day full moon window:

$$
\begin{aligned}
& \text { normvolume }_{j t}=\alpha_{j}+\lambda_{j} * \text { Lunardummy }_{t}+e_{j t} . \\
& \text { volatility }_{j T}=\alpha_{j}+\lambda_{j}{ }^{*} \text { Lunardummy }_{T}+e_{j T},
\end{aligned}
$$

\footnotetext{
${ }^{12}$ Liquidity and market microstructure related issues are likely to have a first-order effect in pricing extreme small stocks rather than mood; hence, a weaker lunar effect for stocks that are extremely small in capitalization is not entirely surprising.
} 
Table 5

Lunar phases, trading volumes, and volatility

\begin{tabular}{|c|c|}
\hline & Lunar dummy $(\lambda)$ \\
\hline \multicolumn{2}{|l|}{ Panel A: trading volumes } \\
\hline Global portfolio (equal-weighted) & $36.27(0.64)$ \\
\hline Pooled regression of 48 countries & $48.802(1.01)$ \\
\hline \multicolumn{2}{|l|}{ Panel B: return volatility } \\
\hline Global portfolio (equal-weighted) & $0.10(0.05)$ \\
\hline Pooled regression of 48 countries & $-0.11(-0.10)$ \\
\hline \multicolumn{2}{|c|}{$\begin{array}{l}\text { Panel A reports test results from estimating the following regressions of daily trading volume on lunar phases for the } \\
\text { global portfolio and a pooled sample of } 48 \text { countries: normvolume }{ }_{j t}=\alpha_{j}+\lambda_{j}{ }^{*} \text { Lunardummy }_{t}+e_{j t} \text {. Normvolume is daily } \\
\text { trading volume normalized by average daily volume in that month. Panel B reports the following regression estimates for } \\
\text { the global portfolio and a pooled sample of } 48 \text { countries: volatility } y_{j}=\alpha_{j}+\lambda_{j} * \text { Lunardummy }{ }_{T}+e_{j T} \text {. Volatility is the } \\
\text { standard deviation of daily logarithmic stock returns in the full moon and the new moon period for each lunar month. } \\
\text { Lunardummy is a dummy variable equal to one during a full moon period and zero during a new moon period. The full } \\
\text { moon period is } 7 \text { days before and after the full moon day plus the full moon day, and the new moon period is the rest of } \\
\text { the lunar month. The estimates of a pooled regression use panel corrected standard errors. The estimates of an OLS } \\
\text { regression use the Newey-West robust standard errors with one lag. T-statistics are reported in the parentheses. } \\
*, * * \text {, and } * * * \text { denote significance at the } 10 \%, 5 \% \text {, and } 1 \% \text { levels, respectively, using a two-tailed test. }\end{array}$} \\
\hline
\end{tabular}

where the variable, normvolume, is the daily trading volume normalized by average daily volume in the month and $t$ is the time index for each day; the variable, volatility, is the standard deviation of daily logarithmic stock returns in a lunar period, and $T$ is the time index for a lunar period.

Test results for Eq. (3) are reported in Table 5, Panel A. The coefficient on Lunardummy is not significant for the portfolio, nor is it significant for the pooled regression of 48 countries, which indicates that there is little evidence that trading volumes are related to lunar phases in a systematic manner. Therefore, the observed lunar effect is not due to patterns in trading volume that are related to lunar phases.

Test results for Eq. (4) are reported in Table 5, Panel B. The coefficients on Lunardummy of the portfolios and the panel regression are of different signs and are both insignificant, which indicates that stock market volatilities are not related to lunar phases in a systematic manner. Hence, the observed lunar effect in stock returns cannot be explained by the risk differentials between the full moon and the new moon periods.

\subsection{Macroeconomic events}

It is possible that the return differential between the full moon and the new moon periods reflects the average effect of macroeconomic events or common market shocks. In this section, we examine to what extent the estimated lunar effect is explained by macroeconomic events. Specifically, we investigate the lunar effect on the global portfolio, controlling for the following three types of events: macroeconomic announcements, major global shocks, and movements in short-term interest rates.

We estimate the lunar effect on the daily logarithmic returns of the global portfolios, controlling for macroeconomic events. Initially, a base case of lunar effect is identified by estimating the following regression for the portfolios at the daily frequency:

$$
R_{t}=\alpha+\beta^{*} \text { Lunardummy }_{t}+e_{t},
$$


where $R_{t}$ is the daily logarithmic return, and $t$ is the time index of daily frequency. The NeweyWest adjusted standard errors are used, assuming an AR1 process. The indicator variable, Lunardummy $_{t}$, is set equal to one if day $t$ falls in a full moon period and zero if day $t$ falls in a new moon period. Eq. (5) is then re-estimated, controlling for macroeconomic announcements, major global shocks, and changes in short-term interest rates.

The test results are reported in Table 6. Model 1 reports the base case. The coefficient $\beta$ on Lunardummy is $-4.26(-5.40)$ bps for the equal-weighted portfolio and $-3.47(-4.77)$ bps for the value-weighted portfolio, for the 15-day (the 7-day) window specification. All estimates are significant at the 5\% level. These results confirm the earlier finding that stock returns are higher during new moon periods than full moon periods.

To examine whether the return differences between the new moon and the full moon periods are due to macroeconomic announcements, two tests are performed. In the first test, Eq. (5) is reestimated by excluding the days with specific macroeconomic announcements: Consumer Price Index, Federal Reserve Open Market Committee announcements, Gross National Product, Retail Sales, Employment Report, Employment Cost Index, Trade Deficit, and National Association of Purchasing Managers Survey Index (following Gerlach, 2004). The resulting $\beta$ estimates,

Table 6

Lunar phases, stock returns, and macro-variables

\begin{tabular}{|c|c|c|c|c|}
\hline & \multicolumn{2}{|l|}{ 15-Day window } & \multicolumn{2}{|l|}{ 7-Day window } \\
\hline & $\begin{array}{l}\text { Equal-weighted } \\
\text { global portfolio }\end{array}$ & $\begin{array}{l}\text { Value-weighted } \\
\text { global portfolio }\end{array}$ & $\begin{array}{l}\text { Equal-weighted } \\
\text { global portfolio }\end{array}$ & $\begin{array}{l}\text { Value-weighted } \\
\text { global portfolio }\end{array}$ \\
\hline \multicolumn{5}{|c|}{ Model 1: global portfolio (base case) } \\
\hline Lunar dummy & $-4.26 * * *(-2.81)$ & $-3.47 * *(-2.03)$ & $-5.40 * *(-2.40)$ & $-4.77 *(-1.89)$ \\
\hline \multicolumn{5}{|c|}{ Model 2: excluding macro-announcement dates } \\
\hline Lunar dummy & $-4.30 * *(-2.40)$ & $-3.65 *(-1.84)$ & $-6.21 * *(-2.40)$ & $-5.37 *(-1.82)$ \\
\hline \multicolumn{5}{|c|}{ Model 3: excluding major global shocks } \\
\hline Lunar dummy & $-3.65 * *(-2.51)$ & $-2.57(-1.50)$ & $-4.07 *(-1.90)$ & $-2.87(-1.15)$ \\
\hline \multicolumn{5}{|c|}{ Model 4: controlling for short-term interest rates } \\
\hline Lunar dummy & $-4.08 * *(-2.66)$ & $-3.02 *(-1.72)$ & $-4.92 * *(-2.16)$ & $-4.02(-1.56)$ \\
\hline Short-term interest rate & $-0.94 * * *(-3.51)$ & $-0.69 * *(-2.32)$ & $-1.12 * * *(-3.05)$ & $-1.30 * * *(-3.21)$ \\
\hline
\end{tabular}

This table compares the returns of global portfolios between the full moon and the new moon periods, excluding macroannouncement dates, periods of major global shocks, or controlling for short-term interest rates. We define the full moon and the new moon periods using the 15-day and the 7-day windows. In the 15-day window specification, we define the full moon period as 7 days before and after the full moon day plus the full moon day, and define the new moon period as the rest of the lunar month. In the 7-day window specification, we define the full (new) moon period as 3 days before and after the full (new) moon day plus the full (new) moon day. Model 1 estimates the following regressions: $R_{t}=\alpha+\beta *$ Lunardummy $_{t}+e_{t}$, where $R_{t}$ is daily logarithmic returns. Lunardummy is a dummy variable equal to one if it is a full moon period and zero if it is a new moon period. Model 2 estimates the model excluding dates for eight macroannouncements: Consumer Price Index, Federal Reserve Open Market Committee announcements, Gross National Product, Retail Sales, Employment Report, Employment Cost Index, Trade Deficit, and National Association of Purchasing Managers Survey Index. Model 3 excludes periods of global shocks: the 1987 U.S. stock market crash (October 19, 1987), the Gulf War (January 17, 1991 to February 17, 1991), the Mexican Peso crisis (December 20,1994 to January 31, 1995), the Asian financial crisis (July 2, 1997 to December 3, 1997), and the Russian crisis (August 11, 1998 to January 15,1999$)$. Model 4 estimates the following regression: $R_{t}=\alpha+\beta *$ Lunardummy $_{t}+\delta *$ short-term interest rate $_{t}+e_{t}$, where short-term interest rate is 3-month Treasury bill rate. Newey-West adjusted $T$-statistics (with one lag) are reported in the parentheses. The daily returns are in basis points.

$*, * *$, and $* * *$ denote significance at the $10 \%, 5 \%$, and $1 \%$ levels, respectively, using a two-tailed test. 


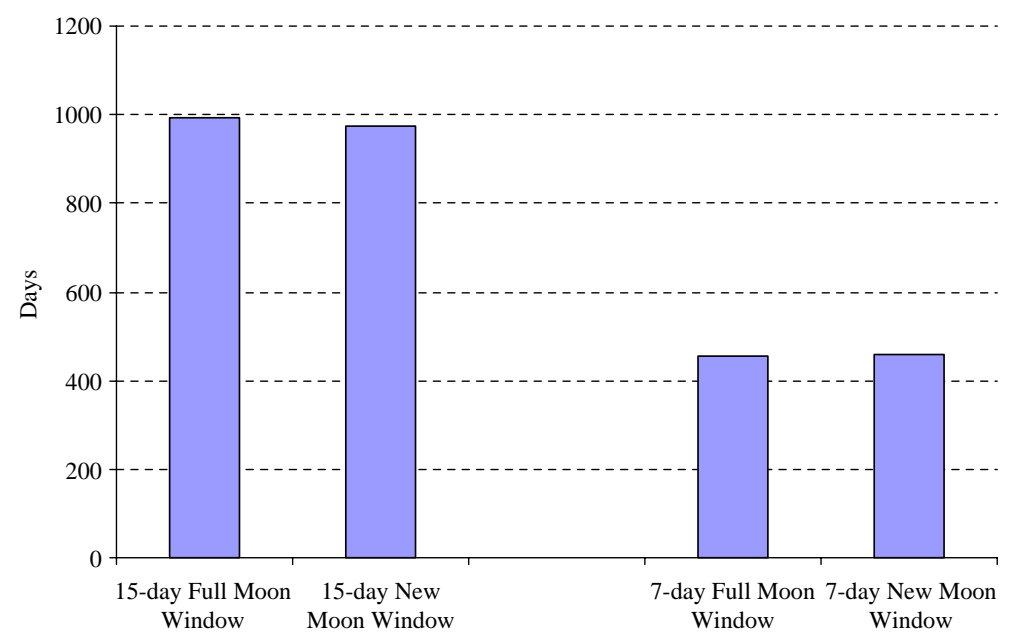

Fig. 3. Distribution of macro-announcement days on full moon and new moon phases. This figure plots the number of announcement dates in full moon and new moon phases in the sample.

reported in Table 6, Model 2, are similar to those of the base case for the 15-day window specification and larger in magnitude for the 7-day window specification, indicating that the lunar effect cannot be explained by the average effect of macroeconomic announcements. In the second test, the number of days with macroeconomic announcement during the new moon and the full moon phases is plotted to compare the distribution of announcements across the lunar periods. Fig. 3 shows that macro-announcements occur quite evenly during the two periods for both the 15-day and the 7-day window specifications. Overall, the evidence indicates that the lunar effect is unlikely due to macroeconomic announcements.

Next, the relevance of global shocks to the lunar effect is examined. Eq. (5) is re-estimated excluding various global shocks. As reported in Table 6, Model 3, the $\beta$ estimates are still negative, albeit smaller in magnitude and lower in statistical significance than the base case. The lunar effect remains negative and significant for the equal-weighted portfolio; the coefficients on Lunardummy are negative but not statistically significant for the value-weighted portfolio. Thus, excluding the periods of global shocks from the analysis weakens the lunar effect to some extent; however, these shocks cannot fully explain the documented lunar effect.

Finally, the lunar effect is examined by controlling for changes in the short-term interest rates. Eq. (5) is modified by including short-term interest rates as an explanatory variable in the following regression:

$$
R_{t}=\alpha+\beta^{*} \text { Lunardummy }_{t}+\delta^{*} \text { Short }- \text { term interest rate }_{t}+e_{t},
$$

where the short-term interest rate is the 3-month Treasury bill rate. The results are presented in Table 6, Model 4. The coefficients on the short-term interest rate are negative for all specifications, indicating that higher interest rates are correlated with lower stock prices. The estimated lunar effect remains similar although slightly weaker, which indicates that changes in short-term interest rates do not explain the observed lunar effect.

Overall, the evidence indicates that the lunar effect cannot be explained away by macroeconomic announcements, common shocks in the stock markets, and changes in shortterm interest rates. 


\subsection{The lunar effect and other calendar anomalies}

This section examines whether the lunar effect can be explained by other calendar anomalies.

\subsubsection{The January effect}

The lunar effect is unlikely a manifestation of the January effect, ${ }^{13}$ since lunar months do not correspond to calendar months. Nevertheless, to test for the relation between the lunar effect and the January effect, a January dummy variable was added to the following regression:

$$
R_{t}=\alpha+\beta^{*} \text { Lunardummy }_{t}+\delta^{*} \text { Januarydummy }_{t}+e_{t} .
$$

Januarydummy is a dummy variable equal to one in the month of January and zero otherwise.

Table 7, Model 1, shows both a significant January effect and a significant lunar effect. Compared with the base case findings in Table 6, where the January effect is not controlled, the magnitude and significance of the lunar effect become only slightly smaller; thus, the January anomaly is not a driving force behind the observed lunar effect.

\subsubsection{Day-of-week effect}

If most full moon days fall on Mondays, it is possible that the Monday effect may explain the observed lunar effect. Fig. 4 shows that the full moon days fall evenly on each day of the week in the sample. In an unreported panel regression of all countries, the estimated lunar effect becomes stronger when the day-of-week fixed effects are included; thus, the lunar effect on stock returns is not related to the day-of-week effect.

\subsubsection{Calendar month effect}

Ariel (1987) shows that the mean U.S. stock return for days during the first half of a calendar month is higher than the mean stock return during the second half of the month. Thus, it is conceivable that the lunar effect documented in this paper may be a manifestation of the calendar month effect. To test for this possibility, a calendar dummy is added in the regression and Eq. (5) is re-estimated, as follows:

$$
R_{t}=\alpha+\beta^{*} \text { Lunardummy }_{t}+\delta^{*} \text { Calendardummy }_{t}+e_{t} .
$$

Calendardummy is a dummy variable equal to one for the first half of a calendar month and zero otherwise. As shown in Model 2 of Table 7, the calendar month effect is not significant for the portfolios; nevertheless, the magnitude and significance of the Lunardummy is consistent with the earlier results. Thus, the test statistics suggest that the calendar month effect cannot explain the observed lunar effect.

\subsubsection{Holiday effect}

Ariel (1990) documents that, on the trading day prior to holidays, stocks advance with disproportionate frequency and show high mean returns averaging 9 to 14 times the mean returns for the other days. To examine this effect, the day before a holiday is excluded for each country. Eq. (5) is then re-estimated using the holiday-adjusted global index returns. As reported in Model 3 of Table 7, the lunar effect is significant at the 5\% level for both portfolios and for both the 15-day and 7-day window specifications. Thus, the lunar effect does not appear to be driven by the holiday effect.

\footnotetext{
13 The January effect has been documented by, for example, Rozeff and Kinney (1976) and Reinganum (1983).
} 
Table 7

Lunar phases, stock returns, and other calendar anomalies

\begin{tabular}{|c|c|c|c|c|}
\hline & \multicolumn{2}{|l|}{ 15-Day window } & \multicolumn{2}{|l|}{ 7-Day window } \\
\hline & $\begin{array}{l}\text { Equal-weighted } \\
\text { global portfolio }\end{array}$ & $\begin{array}{l}\text { Value-weighted } \\
\text { global portfolio }\end{array}$ & $\begin{array}{l}\text { Equal-weighted } \\
\text { global portfolio }\end{array}$ & $\begin{array}{l}\text { Value-weighted } \\
\text { global portfolio }\end{array}$ \\
\hline \multicolumn{5}{|l|}{ Model 1: January effect } \\
\hline Lunar dummy & $-3.98 * * *(-2.58)$ & $-3.00 *(-1.70)$ & $-4.77 * *(-2.09)$ & $-3.96(-1.52)$ \\
\hline January dummy & $13.81 * * *(4.40)$ & $8.20 * *(2.54)$ & $16.67 * * *(3.47)$ & $7.96(1.63)$ \\
\hline \multicolumn{5}{|l|}{ Model 2: calendar effect } \\
\hline Lunar dummy & $-3.99 * * *(-2.59)$ & $-3.01 *(-1.71)$ & $-4.73 * *(-2.07)$ & $-3.92(-1.51)$ \\
\hline Calendar month dummy & $0.66(0.43)$ & $0.56(0.32)$ & $-1.34(-0.60)$ & $-1.19(-0.47)$ \\
\hline \multicolumn{5}{|l|}{ Model 3: holiday effect } \\
\hline Lunar dummy & $-4.24 * * *(-2.79)$ & $-4.78 * * *(-2.59)$ & $-4.82 * *(-2.13)$ & $-7.74 * * *(-2.78)$ \\
\hline \multicolumn{5}{|c|}{ Model 4: lunar holiday effect } \\
\hline Lunar dummy & $-3.76^{* *}(-2.42)$ & $-2.57(-1.44)$ & $-4.33 *(-1.84)$ & $-3.53(-1.31)$ \\
\hline Yomcum dummy & $-17.85(-1.18)$ & $-34.84 * *(-2.23)$ & $5.43(0.69)$ & $-11.83(-0.81)$ \\
\hline Roshcum dummy & $0.46(0.06)$ & $7.21(0.86)$ & $4.49(0.46)$ & $11.93(1.09)$ \\
\hline
\end{tabular}

This table reports regression results of daily logarithmic stock returns on lunar phases (as in Table 6) with controls for other calendar anomalies. Model 1 controls for the January effect. Model 2 controls for the calendar month effect. Model 3 controls for the holiday effect. Model 4 controls for lunar holiday effects. Yomcum dummy is equal to 1 for the day of and the day following Yom Kippur. Roshcum dummy is equal to 1 for the first day of Rosh Hashanah and the following day. Islamic, Hindu, Chinese, and Korean lunar holidays are also controlled for (the coefficient estimates for these lunar holidays are not reported). Newey-West adjusted $T$-statistics (with one lag) are reported in the parentheses. The daily returns are in basis points.

$*$, **, and $* * *$ denote significance at the $10 \%, 5 \%$, and $1 \%$ levels, respectively, using a two-tailed test.

\subsubsection{Lunar holidays}

Frieder and Subrahmanyam (2004) show that Jewish holidays have a significant impact on the U.S. equity market. They find that returns are significantly positive around Rosh Hashanah and significantly negative around Yom Kippur. Two tests are used to check the

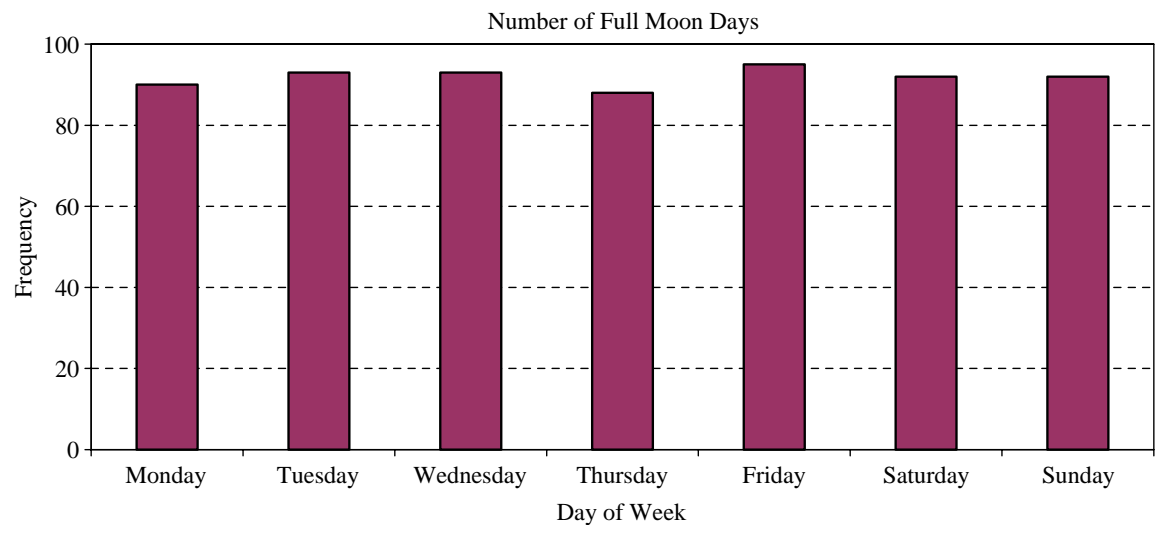

Fig. 4. Distribution of full moon days on days of a week. This figure plots the number of full moon days falling on each weekday during the sample period. 
robustness of the lunar cycle effect: (1) lunar holiday dummy variables are added to Eq. (5) because many Jewish, Islamic, Hindu, Chinese, Japanese, and Korean holidays fall on the fixed days of a lunar-based calendar (Table 7); and (2) lunar holiday dummy variables are added to the estimation of the lunar effect at the country level for relevant countries (Table 8).

Table 7 reports the estimates on the lunar dummy and the lunar holiday dummies for two Jewish holidays: Yom Kippur and Rosh Hashanah. The coefficients for these two holidays are not significant for the portfolios. The coefficient on the lunar dummy for the equalweighted portfolio is -3.76 for the 15 -day window specification and -4.33 for the 7 -day window specification, which are significant at the $5 \%$ and $10 \%$ levels respectively. The coefficient on the lunar dummy for the value-weighted portfolio is -2.57 for the 15-day window specification and -3.54 for the 7-day window specification, both statistically insignificant.

Interestingly, in the country level analysis, the Jewish holiday dummies are statistically significant for the U.S. and the Israeli markets while the lunar holiday dummies for other countries are not significantly different from zero (except in Korea). These results are consistent with the findings for the U.S. stock market in Frieder and Subrahmanyam (2004). For both the U.S. and Israeli market, the returns are lower around Yom Kippur (a somber holiday) and higher around Rosh Hashanah (a cheerful holiday). Nevertheless, the coefficients on the lunar dummies do not change much when the lunar holiday dummies are included, which indicates that the lunar holiday effect is probably independent of the lunar cycle effect. Thus, the observed lunar effect is not likely just a manifestation of other documented calendar anomalies.

Table 8

Lunar holidays

\begin{tabular}{|c|c|c|c|c|c|c|}
\hline & \multicolumn{6}{|c|}{ Independent variables } \\
\hline & Intercept & Lunar dummy & $\begin{array}{l}\text { January } \\
\text { dummy }\end{array}$ & $\begin{array}{l}\text { Yomcum } \\
\text { dummy }\end{array}$ & $\begin{array}{l}\text { Roshcum } \\
\text { dummy }\end{array}$ & $\begin{array}{l}\text { Other lunar } \\
\text { holiday dummy }\end{array}$ \\
\hline U.S. & $3.67 * *(2.00)$ & $-1.89(-0.78)$ & $6.81(1.56)$ & $-39.39 * *(-2.27)$ & $17.44 *(1.67)$ & \\
\hline Israel & $19.01 * * *(5.74)$ & $-11.17 * *(-2.41)$ & $8.49(0.91)$ & $-54.39(-0.80)$ & $71.00 * *(2.15)$ & \\
\hline China & $14.71(1.51)$ & $-8.45(-0.70)$ & $7.34(0.48)$ & & & $34.36(0.93)$ \\
\hline Japan & $3.41 *(1.82)$ & $-4.57 *(-1.81)$ & $8.71 *(1.79)$ & & & $0.23(0.03)$ \\
\hline Korea & $-2.49(-0.74)$ & $1.96(0.27)$ & $27.62 *(1.74)$ & & & $94.32 *(1.77)$ \\
\hline India & 9.96* (1.84) & $-8.15(-1.11)$ & $7.98(0.62)$ & & & $-11.87(-0.48)$ \\
\hline Indonesia & $7.77(1.28)$ & $-19.23 * *(-2.23)$ & $25.66(1.48)$ & & & $-48.29(-0.52)$ \\
\hline Jordan & $2.54(0.91)$ & $-1.23(-0.32)$ & $8.90(1.29)$ & & & $-1.26(-0.10)$ \\
\hline Malaysia & $7.16^{*}(1.73)$ & $-8.28(-1.43)$ & $0.26(0.02)$ & & & $23.58(1.60)$ \\
\hline Morocco & $12.15 * * *(3.84)$ & $-1.39(-0.31)$ & $9.03(0.91)$ & & & $-9.37(-1.13)$ \\
\hline Pakistan & $3.46(0.74)$ & $-1.17(-0.18)$ & $-2.30(-0.19)$ & & & $-3.10(-0.14)$ \\
\hline Turkey & $22.98 * *(2.95)$ & $-12.62(-1.20)$ & $52.28 * *(2.40)$ & & & $3.08(0.10)$ \\
\hline
\end{tabular}

This table reports the 15-day window regression results of daily logarithmic stock returns on lunar phases controlling for the January effect and the lunar holiday effect. Yomcum dummy is equal to one for the day of and the day following Yom Kippur. Roshcum dummy is equal to one for the first day of Rosh Hashanah and the day following. Other lunar holiday dummies are country/religion specific. Newey-West adjusted $T$-statistics (with one lag) are reported in the parentheses. The daily returns are in basis points.

$* * *, * *, *$ indicate $1 \%, 5 \%, 10 \%$ significance levels respectively using a two-tailed test. 
Table 9

Lunar phases, stock returns, and varying lunar window length

\begin{tabular}{lll}
\hline Window length & \multicolumn{2}{l}{ Lunar dummy $(\beta)$} \\
\cline { 2 - 3 } & Equal-weighted global portfolio & Value-weighted global portfolio \\
\hline 15 Days & $-4.26^{* * *}(-2.81)$ & $-3.47^{* *}(-2.03)$ \\
13 Days & $-4.55^{* * *}(-2.76)$ & $-3.42^{*}(-1.86)$ \\
9 Days & $-5.00^{* * *}(-2.77)$ & $-3.16(-1.56)$ \\
7 Days & $-5.23^{* *}(-2.60)$ & $-3.95^{*}(-1.76)$ \\
5 Days & $-5.40^{* *}(-2.40)$ & $-4.77^{*}(-1.89)$ \\
3 Days & $-4.83^{*}(-1.93)$ & $-4.77^{*}(-1.68)$ \\
1 Day & $-5.64 *(-1.82)$ & $-6.75^{*}(-1.91)$ \\
\hline
\end{tabular}

The following regressions are estimated: $R_{t}=\alpha+\beta *$ Lunardummy $_{t}+e_{t}$, where $R_{t}$ is daily logarithmic returns. Lunardummy is a dummy variable indicating the phase of a lunar cycle. We define a full moon period as $N$ days before the full moon day + the full moon day $+N$ days after the full moon day $(N=0$ to 7$)$. Similarly, we define a new moon period as $N$ days before the new moon day + the new moon day $+N$ days after the new moon day $(N=0$ to 7). Lunardummy is equal to one during a full moon period and zero during a new moon period. Window length is $2 * N+1$. Newey-West adjusted $T$-statistics (with one lag) are reported in the parentheses. The daily returns are in basis points. $*, * *$, and $* * *$ denote significance at the $10 \%, 5 \%$, and $1 \%$ levels, respectively, using a two-tailed test.

\subsection{Additional robustness checks}

The robustness of the lunar effect was further checked by examining various lunar window lengths, alternative ARIMA specifications, and a test of random 30-day cycles.

\subsubsection{Lunar window length}

To address the concern that the estimated lunar effect may be due to the choice of window length, Eq. (5) is re-estimated for window lengths of 1 to 15 (Table 9). The stock returns are higher during the new moon phases than the full moon phases for all window lengths for both portfolios. Except for the 1-day window, the $p$-values of all estimates are lower than the $10 \%$ level of significance. Consistent with the earlier findings, except for the 3 -day window, the lunar effect is stronger and more significant for the equal-weighted portfolio than for the value-weighted portfolio. Since the return differences are quite consistent across the window lengths, it is unlikely that the lunar effect is due to the choice of window length.

\subsubsection{ARIMA}

Different ARIMA specifications are used to adjust the returns of the portfolios. Eq. (5) is then re-estimated (Table 10). Both the magnitude and the statistical significance of the $\beta$ estimates are consistent across the different specifications, indicating that the documented lunar effect is not due to the time-series properties of stock returns.

\subsubsection{0-Day cycle effect}

To test whether the observed lunar effect reflects a general pattern in stock returns, rather than a lunar-driven cycle, the lunar phase is shifted by 1 to 29 days. That is, a 30-day cycle is started on day 1 to 29 after the first full moon day, and the 30-day cycle effect is estimated for each specification, using the following pooled regression with PCSE:

$$
R_{i t}=\alpha_{i}+\beta^{*} 30 \text { daydummy }_{t}+e_{i t},
$$


Table 10

Lunar phases, stock returns, and ARIMA specifications

\begin{tabular}{lll}
\hline & \multicolumn{2}{l}{ Lunar dummy $(\beta)$} \\
\cline { 2 - 3 } & Equal-weighted global portfolio & Value-weighted global portfolio \\
\hline ARIMA $(1,1)$ & $-4.12^{* *}(-2.66)$ & $-3.71 * *(-2.05)$ \\
ARIMA $(1,0)$ & $-4.08^{* * *}(-2.60)$ & $-3.60 *(-1.93)$ \\
ARIMA $(0,1)$ & $-4.14^{* * *}(-2.76)$ & $-3.71 * *(-2.04)$ \\
ARIMA $(1,2)$ & $-4.11^{* * *}(-2.82)$ & $-3.73 * *(-2.07)$ \\
ARIMA $(2,1)$ & $-4.10^{* *}(-2.64)$ & $-3.74 * *(-2.09)$ \\
\hline
\end{tabular}

ARIMA specifications are estimated for the daily logarithmic returns of the portfolios and then the following regression is estimated: $R_{t}=\alpha+\beta *$ Lunardummy $_{t}+e_{t}$, where $R_{t}$ is the residual of the ARIMA model. Lunardummy is a dummy variable indicating the phase of a lunar cycle, equal to one during a full moon period and zero during a new moon period. The full moon period is 7 days before and after the full moon day plus the full moon day, and the new moon period is the rest of the lunar month. $T$-statistics are reported in the parentheses. The daily returns are in basis points.

$*, * *$, and $* * *$ denote significance at the $10 \%, 5 \%$, and $1 \%$ levels, respectively, using a two-tailed test.

where $R_{i t}$ is the daily logarithmic return for country $i$ and date $t$, and 30daydummy is a dummy variable that indicates the phase of a 30-day cycle. The 30daydummy takes on a value of one for 7 days before the starting day + the starting day +7 days after the starting day, and a value of zero otherwise.

Table 11 shows that the 30-day cycle effects for the cycles starting 1 to 8 days and 24 to 29 days after the full moon display negative signs. Moreover, the statistical significance of the estimated 30-day cycle effect declines as these 30-day cycles deviate more from the lunar cycle. In fact, for the cycles starting 10 to 23 days after the full moon, the pattern is reversed. Fig. 5

\begin{tabular}{|c|c|c|c|}
\hline$N$ & $\beta$ & $N$ & $\beta$ \\
\hline 1 & $-3.37 * * *(-4.11)$ & 16 & $2.73 * * *(3.33)$ \\
\hline 2 & $-3.28 * * *(-4.00)$ & 17 & $3.40 * * *(4.14)$ \\
\hline 3 & $-2.69 * * *(-3.28)$ & 18 & $2.53 * * *(3.08)$ \\
\hline 4 & $-3.44 * * *(-4.19)$ & 19 & $2.54 * * *(3.08)$ \\
\hline 5 & $-3.07 * * *(-3.74)$ & 20 & $3.17 * * *(3.85)$ \\
\hline 6 & $-3.19 * * *(-3.88)$ & 21 & $2.39 * * *(2.90)$ \\
\hline 7 & $-0.85(-0.03)$ & 22 & $0.10(0.72)$ \\
\hline 8 & $-0.27(-0.33)$ & 23 & $0.75(0.96)$ \\
\hline 9 & $0.22(0.27)$ & 24 & $-0.80(-1.03)$ \\
\hline 10 & $1.32(1.60)$ & 25 & $-1.49 *(-1.92)$ \\
\hline 11 & $3.44 * * *(4.19)$ & 26 & $-3.63 * * *(-4.67)$ \\
\hline 12 & $3.89 * * *(4.74)$ & 27 & $-4.44 * * *(-5.71)$ \\
\hline 13 & $4.26^{* * *}(5.19)$ & 28 & $-4.10 * * *(-5.27)$ \\
\hline 14 & $4.16^{* * *}(5.07)$ & 29 & $-3.85 * * *(-4.95)$ \\
\hline 15 & $4.48 * * *(5.45)$ & 30 & $-4.55(-5.55)$ \\
\hline
\end{tabular}

This table reports the estimates of a pooled regression with panel corrected standard errors (PCSE): $R_{i t}=\alpha_{i}+\beta * 30$ daydummy $_{t}+e_{i t}$ for a 15-day window when lunar phases are shifted by $N$ calendar days. A 30-day cycle is started $N$ days after the first full moon $(N=1$ to 29$)$, and then the 30-day cycle effect is estimated. 30daydummy takes on a value of one for 7 days before the starting day + the starting day +7 days after the starting day, and a value of zero otherwise. The lunar cycle is represented by $N=0 . T$-statistics are in parentheses. The daily logarithmic returns are in basis points.

$*$, **, and $* * *$ denote significance at the $10 \%, 5 \%$, and $1 \%$ levels, respectively, using a two-tailed test. 


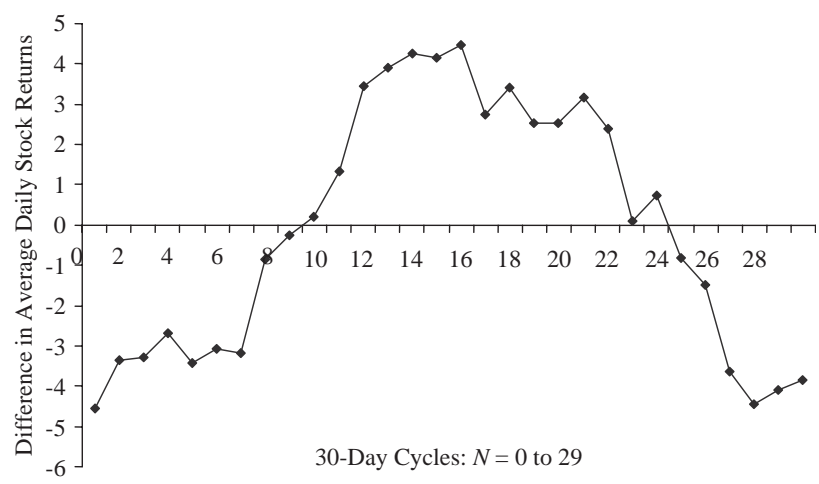

Fig. 5. 30-Day cycles and stock returns. This figure graphs the estimates of pooled regressions with panel corrected standard errors (PCSE): $R_{i t}=\alpha_{i}+\beta * 30$ daydummy ${ }_{t}+e_{i t}$ for a 15-day window when lunar phases are shifted by $N$ calendar days. More specifically, a 30-day cycle of $N$ days is started after the first full moon ( $N=1$ to 29), and the 30-day cycle effect is estimated for each specification. 30daydummy takes on a value of one for 7 days before the starting day + the starting day +7 days after the starting day, and a value of zero otherwise. The lunar cycle is represented by $N=0$. The $X$-axis indicates 30 -day cycles ordered by $N$. The $Y$-axis marks $\beta$ estimates. The daily returns are in basis points.

graphs the estimates of the 30-day cycle effect and shows that the documented lunar effect cannot arise from any 30-day cycle except for those that closely track the lunar cycle.

Overall, the findings indicate that the lunar effect on stock returns is robust to various lunar window lengths, alternative ARIMA specifications of the stock returns, and a test of random 30day cycles.

\section{Conclusion}

This paper investigates the relation between lunar phases and stock returns for a sample of 48 countries. Strong global evidence indicates that stock returns are lower on days around a full moon than on days around a new moon. The return differences are statistically and economically significant during the sample period. Since lunar phases are likely to be related to investor mood and are not related to economic activities, the findings are thus not consistent with the predictions of traditional asset pricing theories that assume fully rational investors. The positive association identified between lunar phases and stock returns suggests that it might be valuable to go beyond a rational asset pricing framework to explore investor behavior.

The psychology literature has provided numerous theories on how mood affects perceptions and preferences. One theory is that mood affects perception through misattribution: attributing feelings to wrong sources leads to incorrect judgments (Schwarz and Clore, 1983; Frijda, 1988). Alternatively, mood may affect people's ability to process information. In particular, investors may react to salient or irrelevant information when feeling good (Schwarz, 1990; Schwarz and Bless, 1991). Finally, mood may affect preferences (Loewenstein, 2000; Mehra and Sah, 2000). This paper is a first step toward documenting the possible effect of mood on asset prices. It would be interesting to better understand how mood affects asset prices. In a survey paper, Hirshleifer (2001) pointed out that one area of future research is to conduct experimental testing of behavioral hypotheses. In a related vein, future work could study the effect of mood on asset prices in an experimental setting. For example, does investment behavior in experimental settings differ during different phases of a lunar cycle? 


\section{Acknowledgements}

We are grateful to two anonymous referees, Geert Bekaert (the editor), Keith Brown, Kathy Clark, William Goetzmann, Campbell Harvey, David Hirshleifer, Han Kim, Nancy Kotzian, M.P. Narayanan, Emre Ozdenoren, Scott Richardson, Tyler Shumway, Warren Zhang and seminar participants at the University of Michigan, Michigan State University, and University of Texas at Austin for helpful comments. We thank Jing Wang for research assistance. All errors are our own.

\section{References}

Agus, M.D., 1973. The rejection of two explanations of belief in a lunar influence on behavior, Unpublished master's thesis, Simon Fraser University, Burnaby, British Columbia, Canada.

Ariel, R.A., 1987. A monthly effect in stock returns. Journal of Financial Economics 18, 161-174.

Ariel, R.A., 1990. High stock returns before holidays: existence and evidence on possible causes. Journal of Finance 45, $1611-1626$.

Avery, C., Chevalier, J., 1999. Identifying investor sentiment from price paths: the case of football betting. Journal of Business 72, 493-521.

Beck, N., Katz, J.N., 1995. What to do (and not to do) with time-series cross-section data. The American Political Science Review 89, 634-647.

Campbell, D.E., Beets, J.L., 1978. Lunacy and the moon. Psychological Bulletin 85, 1123-1129.

Coval, J.D., Shumway, T., 2005. Do behavioral biases affect prices? Journal of Finance 60 (1), 1-34.

Criss, T.B., Marcum, J.P., 1981. A lunar effect on fertility. Social Biology 28, 75-80.

Cyr, J.J., Kaplan, R.A., 1987. The lunar-lunacy relationship: a poorly evaluated hypothesis. Psychological Reports 62 , $683-710$.

Danzl, D.F., 1987. Lunacy. Journal of Emergency Medicine 5, 91-95.

De Castro, J.M., Pearcey, S.M., 1995. Lunar rhythms of the mean and alcohol intake of humans. Physiology and Behavior 57, 439-444.

Dichev, I.D., Janes, T.D., 2003. Lunar cycle effects in stock returns. Journal of Private Equity 6 (Fall), 8-29.

Frieder, L., Subrahmanyam, A., 2004. Non-secular regularities in stock returns and volume. Financial Analysts Journal 60 (4), $29-34$.

Frijda, N., 1988. The laws of emotion. Cognition and Emotion 1, 235-258.

Garzino, S.J., 1982. Lunar effects on mental behavior: a defense of the empirical research. Environment and Behavior 14, $395-417$.

Gerlach, J.R., 2004. The arrival of information and stock market calendar anomalies, Working paper, College of William and Mary.

Harlow, W.V., Brown, K.C., 1990. Understanding and assessing financial risk tolerance: a biological perspective. Financial Analysts Journal 46, 50-62.

Hicks-Caskey, W.E., Potter, D.R., 1991. Weekends and holidays and acting-out behavior of developmentally delayed women: a reply to Dr. Mark Flynn. Perceptual and Motor Skills 74, 1375-1380.

Hirshleifer, D., 2001. Investor psychology and asset pricing. Journal of Finance 56 (4), 1533-1598.

Hirshleifer, D., Shumway, T., 2003. Good day sunshine: stock returns and the weather. Journal of Finance 58, $1009-1032$.

Kamstra, M.J., Kramer, L.A., Levi, M.D., 2000. Losing sleep at the market: the daylight-savings anomaly. American Economic Review 90 (4), 1000-1005.

Kamstra, M.J., Kramer, L.A., Levi, M.D., 2003. Winter blues: seasonal affective disorder (SAD) and stock market returns. American Economic Review 93 (1), 324-343.

Katzeff, K., 1981. Moon Madness. Citadel Press, Secaucus, N.J.

Kelley, D.M., 1942. Mania and the moon. Psychoanalytic Review 9, 406-426.

Law, S.P., 1986. The regulation of menstrual cycle and its relationship to the moon. Acta Obstetricia et Gynecologica of Scandinavica $65,45-48$.

Liber, A., 1978. Human aggression and lunar synodic cycle. Journal of Clinical Psychiatry 39 (5), 385.

Loewenstein, G.F., 2000. Emotion in economic theory and economic behavior. American Economic Review 65, $426-432$. 
Mehra, R., Sah, R., 2000. Mood, projection bias and equity market volatility, Working paper, University of California, Santa Barbara.

Neal, R.D., Colledge, M., 2000. The effect of the full moon on general practice consultation rates. Family Practice 17 (6), $472-474$.

Newey, W.K., West, K.D., 1987. A simple positive semi-definite, heteroscedasticity and autocorrelation consistent covariance matrix. Econometrica 55, 703-708.

Odean, T., 1998. Are investors reluctant to realize their losses? Journal of Finance 53, 1775-1798.

Odean, T., 1999. Do investors trade too much? American Economic Review 89, 1279-1298.

Raison, C.L., 1999. The moon and madness reconsidered. Journal of Affective Disorders 53, 99-106.

Reinganum, M., 1983. The anomalous stock market behavior of small firms in January: empirical test for tax-loss selling effects. Journal of Financial Economics 12, 89-104.

Rotton, J., Rosenberg, M., 1984. Lunar Cycles and the Stock Market: Time-Series Analysis for Environmental Psychologists, Unpublished manuscript, Florida International University, North Miami, Florida.

Rotton, J., Kelly, I.W., 1985a. A scale for assessing belief in lunar effects: reliability and concurrent validity. Psychological Reports 57, 239-245.

Rotton, J., Kelly, I.W., 1985b. Much ado about the full moon: a meta-analysis of lunar-lunacy research. Psychological Bulletin 97, 286-306.

Rozeff, M., Kinney Jr., W., 1976. Capital market seasonality: the case of stock returns. Journal of Financial Economics 3 , $379-402$.

Sands, J.M., Miller, L.E., 1991. Effects of moon phase and other temporal variables on absenteeism. Psychological Reports 69, 959-962.

Saunders, E.M.J., 1993. Stock prices and Wall Street weather. American Economic Review 83, 1337-1345.

Schwarz, N., 1990. Feelings as informational and motivational functions of affective states. In: Sorrentino, R., Higgins, E.T. (Eds.), Handbook of Motivation and Cognition vol. 2. Guilford Press, New York, pp. 527-561.

Schwarz, N., Bless, H., 1991. Happy and mindless, but sad and smart? The impact of affective states on analytic reasoning. In: Forgas, J. (Ed.), Emotion and Social Judgments. Pergamon, Oxford, pp. 55-71.

Schwarz, N., Clore, G.L., 1983. Mood, misattribution, judgments of well-being: informative and directive functions of affective states. Journal of Personality and Social Psychology 45, 513-523.

Sias, R.W., Starks, L.T., 1997. Institutions and individuals at the turn-of-the-year. Journal of Finance 52, $1543-1562$.

Sullivan, R., Timmermann, A., White, H., 1999. Data snooping, technical trading rule performance, and the bootstrap. Journal of Finance 54, 1647-1692.

Szpir, M., 1996. Lunar phases and climatic puzzles. American Scientist 86, 119-120.

Tasso, J., Miller, E., 1976. Effects of full moon on human-behavior. Journal of Psychology 93, 81-83.

Vance, D.E., 1995. Belief in lunar effects on human behavior. Psychological Reports 76, 32-34.

Weiskott, G.N., 1974. Moon phases and telephone counseling calls. Psychological Reports 35, 752-754. 